Revista Iberoamericana, Vol. LXXVI, Núm. 231, Abril-Junio 2010, 477-492

\title{
DE PEPE CARVALHO AL SUBCOMANDANTE MARCOS: LA NOVELA POLICÍACA HISPÁNICA Y LA GLOBALIZACIÓN
}

POR

José F. COLMEIRO

Michigan State University

Cuando se decretó la dictadura de la teología neoliberal en los años noventa del siglo xx, cualquier resto de cultura emancipadora o simplemente contestataria fue señalado como muestra residual de las utopías o nostalgias revolucionarias del siglo $\mathrm{xx}$, pero el siglo xxı ha inutilizado este discurso ante la evidencia de que el supuesto nuevo orden internacional recuerda demasiado al antiguo desorden, aunque un nuevo lenguaje trate de balsamizar la cruda tensión entre globalizadores y globalizados

M. Vázquez Montalbán, "Porto Alegre”

Alguien advirtió que ir contra la globalización era como ir contra la ley de la gravedad. Así que ni modo, jabajo la ley de la gravedad!

Subcomandante Marcos

Cuando Santo Domingo se llamaba “Ciudad Trujillo” y Ferrol se apellidaba “El Ferrol del Caudillo”, cuando Latinoamérica y España eran presas de feroces dictaduras militares, con caudillos amparados por el paternalismo norteamericano, y el mundo vivía bajo la amenaza de la guerra fría, oír hablar de novela policíaca hispánica podría hacer sonreír, sonrojar o enfurecer a cualquiera. No resultaba apropiado, creíble, o permisible. Sólo Sam Spade, Philip Marlowe, Poirot o Maigret, tenían licencia para investigar. El mundo hispano era diferente. Las razones que los críticos aducían para explicar esta situación de ausencia se basaban en el esencialismo étnico -la particular idiosincrasia latina frente al racionalismo y cientificismo anglosajón-, la predilección del público por los ambientes exóticos escapistas alejados de la realidad cercana, o la profecía autocumplida -la falta de tradición autóctona y, por 
lo tanto, la inverosimilitud literaria. Un artículo de Juan del Arco publicado en las páginas de El Español de Madrid en 1948 resumía ejemplarmente en su título esta situación: "El detective no puede llamarse Fernández".

Sin embargo, habría otras razones de mayor peso que explicarían esta ausencia de una novela policíaca autóctona, como la falta generalizada en el ámbito hispánico de estados de derecho apoyados en un orden jurídico burgués que garantice las libertades individuales, que es la base histórica e ideológica del género policíaco tradicional, y el añadido del estigma subliterario del género, de difícil legitimación por su empobrecido capital simbólico (Bourdieu), que alejaba a los autores de ambiciones literarias. ${ }^{1}$ Lo que sin duda no faltaba en el ámbito hispánico eran casos por investigar, y todas las previsiones sobre la supuesta inexistencia de este género o imposibilidad en el mundo hispánico resultaron erróneas, como veremos más adelante. El ocaso de las dictaduras y la iniciación de procesos de transición democrática en el mundo hispánico en los años setenta y ochenta, así como la apertura de nuevos canales internacionales de comercio y consumo cultural, allanarían el terreno para la irrupción de la novela policíaca hispánica como uno de los instrumentos privilegiados para la crónica cultural del momento histórico. La celebración anual de la "Semana Negra” internacional de Gijón, dirigida por el escritor astur-mexicano Paco Ignacio Taibo II es sólo la muestra más espectacular de la mayoría de edad de la novela policíaca hispana en la era global. ${ }^{2}$

En este trabajo me voy a centrar en el análisis del proyecto del escritor catalán Manuel Vázquez Montalbán, en el hecho de ser precursor de la literatura hispánica de la novela policíaca negra, subvirtiendo el género y adaptándolo a un nuevo contexto político y cultural, que ha servido de referente para muchos otros autores en español, desde Paco Ignacio Taibo II al Subcomandante Marcos, al igual que en otras lenguas. Mi ensayo va a examinar el alcance e impacto de su obra policíaca en la cultura contemporánea, como uno de los principales "proyectos descolonizadores del género”, tal y como ha señalado Taibo II (38). Este análisis resulta especialmente pertinente en el contexto de la globalización económica y cultural dada la muy extensa y diseminada obra policíaca de Vázquez Montalbán, desarrollada a lo largo de tres décadas en novelas y cuentos (1972-2004), traducida a unos veinte idiomas, y adaptada en múltiples ocasiones tanto al teatro, como al cine y a la televisión, y

1 Los cuentos policíacos naturalistas de Pardo Bazán, o los cuentos policíacos “metafísicos” de Borges (Holquist) representan casos excepcionales, que en ningún caso llegaron a generar una tradición de género autóctona.

2 Para Taibo II, la relevancia actual del género policíaco en los países hispánicos se debe a que "te permite vincular el momento en que una sociedad rompe sus apariencias y se muestra tal cual es. Y en nuestros países, el policial te da un diagnóstico del poder” (Friera).

Revista Iberoamericana, Vol. LXXVI, Núm. 231, Abril-Junio 2010, 477-492
ISSN 2154-4794 (Electrónico) 
que además de relatos se constituye de un sinfín de artículos, manifiestos, prólogos, conferencias y entrevistas sobre el género policíaco. ${ }^{3}$

Mi análisis de la trayectoria de Vázquez Montalbán dentro de un contexto global se articula alrededor de dos núcleos principales; por un lado, en cuanto al propio desarrollo de su novelística inmerso en unas corrientes históricas, ideológicas y económicas mundiales más allá de las fronteras geopolíticas nacionales, lo cual se refleja a su vez en la propia temática de su obra, siempre autoconsciente de su inclusión dentro de un orden internacional determinado y su atención a los procesos globalizadores; y, por otro lado, en cuanto a la propia configuración de Vázquez Montalbán como autor, figura pública y referente intelectual dentro del mercado global. Propongo que la trayectoria de Vázquez Montalbán, plenamente inmersa en las tensiones de la sociedad capitalista tardía, representa un ejemplo de respuesta y resistencia frente a esas corrientes de política económica neoliberal y culturalmente homogeneizadoras y adaptables a las exigencias del mercado. Vázquez Montalbán se convertiría, así, en una figura emblemática de la lucha de resistencia contra los efectos negativos de la globalización, utilizando los mismos medios de comunicación masiva que la globalización económica y tecnológica pone a su alcance, de la misma manera que otras figuras mediáticas del mundo hispánico, como pueden ser el Subcomandante Marcos o Manu Chao.

Iniciamos este recorrido con un flashback. En 1956, un intelectual vasco exiliado en la República Dominicana tras la guerra civil española termina su tesis doctoral en la Universidad de Columbia sobre "La era de Trujillo". Su nombre era Jesús de Galíndez. Habiendo escapado de la dictadura franquista en 1939, Galíndez se enfrenta ahora a la dictadura de Trujillo, y es presionado por agentes trujillistas para no publicar su libro, que constituía una denuncia abierta de la dictadura dominicana. Misteriosamente, Galíndez “desaparece” en Nueva York sin dejar rastro, para nunca más volver a aparecer. Poco a poco, varios de los implicados, cómplices, partícipes o testigos de la desaparición de Galíndez, fueron desapareciendo a su vez en similares situaciones. A raíz de la desaparición de un ciudadano norteamericano se inició una investigación en el congreso de los EE.UU. sobre el caso Galíndez. Se sospechaba que el rapto y asesinato de Galíndez fue ordenado directamente por Trujillo, que con un fuerte lobby de presión en Washington, se sentía protegido para actuar con plena impunidad. El caso Galíndez recibió gran atención en los medios informativos de la época en todo el mundo, sin embargo, aunque acabaría siendo el detonante del final del trujillismo unos pocos años más tarde, lo cierto es que se le echó tierra por encima, para quedar como un misterio real, nunca del todo resuelto, incluso hoy casi 50 años más tarde.

\footnotetext{
3 Para un panorama general, véase el índice de bibliografía en Colmeiro, Crónica del desencanto.
}

年)


Un joven Vázquez Montalbán se enteró del caso Galíndez cuando era un recién llegado a la Universidad de Ciencias de la Información de Barcelona, a finales de los años 50, y durante muchos años lo conservó como un referente moral del intelectual frente a la barbarie del siglo xx -testimonio de la impunidad de las torturas y los crímenes políticos-, implicaba la lucha contra los imperialismos y la necesidad de memoria histórica como forma de resistencia. Reflejos de este interés de Vázquez Montalbán por Galíndez ya aparecían en forma embrionaria incluso en su primeriza novela Yo maté a Kennedy, iniciada en 1967 y publicada en 1972.

Hacemos ahora un flashforward. Bastantes años más tarde, en 1990, Vázquez Montalbán da finalmente a la luz su novela Galíndez, fruto de una larguísima gestación de varias décadas de maduración e investigación exhaustiva. Galíndez es la primera novela del autor que responde directamente a las proclamas de la emergente globalización desde una óptica posmoderna. Galíndez constituye un tour de force novelístico de enorme envergadura, una novela de investigación y de denuncia, en la que quedan implicados, no sólo el aparato militar de Trujillo, el laissez faire de la España franquista y la amnesia histórica de la España socialista, sino también las oscuras tramas de los servicios secretos de los Estados Unidos, y la colaboración del Partido Nacionalista Vasco (e incluso del propio Galíndez) en los mismos, dentro de la común causa anticomunista. Es una novela fundamentalmente híbrida y poliédrica, donde se mezclan heterogéneos ingredientes de la novela de investigación, con personajes de la novela histórica, la indagación subjetiva de la novela de la memoria, el cuestionamiento de las grandes narrativas de la metaficción historiográfica posmoderna, el suspenso del thriller político y el imperativo moral de la literatura testimonial. No es casual que esta novela se publicara precisamente en 1990, cuando la nueva cara del nuevo orden mundial se empieza a conocer con el nombre de globalización. Tras la caída del telón de acero, el ocaso de las ideologías, la aceleración de la historia y la erosión de la memoria, la intensificación de las comunicaciones y tecnologías, los flujos humanos a escala global, todo queda bajo un orden neoimperial supranacional que impone una hegemonía política, económica y cultural.Ante este devastador panorama, Vázquez Montalbán parece preguntarse: ¿Qué sentido tiene la resistencia moral frente a la lógica aplastante del mercado? ¿Puede la memoria histórica servir de antídoto a la erosión de la identidad cultural, y de código ético frente a la impunidad?

En esta obra Vázquez Montalbán procede a la desterritorialización de la novela policíaca, tanto en cuanto a la redefinición de sus propias fronteras genéricas, como a su constante transgresión de las fronteras geopolíticas. La acción de la novela se desplaza por una variedad de localizaciones globales, en rincones apartados de una geografía físicamente dispersa pero subrepticiamente atada por complejas conexiones político-económicas. El tejido narrativo se constituye como un collage

Revista Iberoamericana, Vol. LXXVI, Núm. 231, Abril-Junio 2010, 477-492
ISSN 2154-4794 (Electrónico) 
de viñetas también invisiblemente hilvanadas que reflejan las tensiones en la España autonómica entre la periferia del País Vasco y el centralismo del Madrid socialista, en las tercermundistas provincias del imperio como Santo Domingo y su relación de dependencia de los centros neoimperiales del norte, Miami, Nueva York, y la invisible pero panóptica ciudad de Washington, desde donde se vigilan los movimientos de resistencia y se organizan las ocultas tramas de la historia.

Galíndez es una novela de factura posmoderna, fragmentada, heteroglósica, contradictoria, repleta de fisuras narrativas y saltos temporales, autorreflexiva, permanentemente fluctuante y caleidoscópica, y, al mismo tiempo, con enorme fluidez y una gran agilidad narrativa, repleta de intrigas y misterios que atrapan al lector en su red narrativa. A su vez, la constante fluctuación espacio-temporal de la novela refuerza las conexiones históricas entre pasado y presente, así como entre metrópoli y colonia. Galíndez podría representar un modelo de una nueva novela policíaca hispánica, de carácter global, tanto por su constitución heterogénea transnacional y poliglósica, por su temática que analiza los vínculos políticos, ideológicos, económicos y culturales neoimperiales, como por su alcance y difusión más allá de las fronteras nacionales, en múltiples ediciones y traducida a ocho idiomas y recipiente de varios prestigiosos premios, incluidos el Premio de las Letras en España y el Premio de literatura de la Unión Europea. La exitosa novela de género La reina del Sur, de Arturo Pérez Reverte, otro thriller poliglósico transnacional que refleja las oscuras conexiones transatlánticas globales, tiene su precursor en Galíndez. Por otro lado, la literatura de denuncia de la dictadura trujillista sigue una línea que va de La era de Trujillo hasta Galíndez, y novelas históricas como El tiempo de las mariposas de Julia Alvarez, Soldados de porcelana de Horacio Vázquez Rial, o La fiesta del chivo de Mario Vargas Llosa, serían sus herederas indirectas más claras. La reciente versión cinematográfica de la novela de Vázquez Montalbán, llevada a cabo por Gerardo Herrero y titulada El misterio Galíndez (The Galíndez File en inglés), y que es una coproducción internacional hispano-americana bilingüe, en inglés y español, con un elenco artístico también internacional que incluye al norteamericano Harvey Keitel y a la inglesa Saffron Burrows, rodada en España, Cuba y Canadá, refleja a la vez la creciente erosión del "cine nacional” y amplía aún más el alcance global de esta narrativa.

Si bien Galíndez es la novela en singular de Vázquez Montalbán que quizás mejor representa la globalización de la novela policíaca en el mundo hispano en sus múltiples aspectos, la totalidad de su obra policíaca se hace eco de los procesos de globalización en línea progresivamente ascendente. El personaje literario que precede a Galíndez e hizo internacionalmente conocido a Vázquez Montalbán, el detective privado Pepe Carvalho, ha dado origen a una extremadamente popular serie narrativa de más de 30 años de vida. Desde el mismo comienzo de la serie

Revista Iberoamericana, Vol. LXXVI, Núm. 231, Abril-Junio 2010, 477-492
ISSN 2154-4794 (Electrónico) 
Carvalho, existe en ella ya una muy clara conciencia de pertenencia a un orden mundial político y económico preestablecido, determinado por el reparto geopolítico de la guerra fría en dos bloques ideológicos. La primera novela de Carvalho, Yo maté a Kennedy, escrita entre 1967 y 1971, se gesta en un momento de crisis de ese orden mundial, cuando las posibilidades de resquebrajar el orden establecido desde dentro parecían verdaderamente posibles. El personaje de Pepe Carvalho surge en Yo maté como respuesta a los acontecimientos globales de 1968 y la frustración de las grandes expectativas despertadas entre los intelectuales españoles de entonces a raíz del mayo francés, la primavera de Praga, las revueltas tras la sangrienta masacre de Tlatelolco en México y el eco amortiguado por la censura de todos aquellos movimientos internacionales contestatarios, pacifistas y anti-imperialistas en los años finales de la dictadura franquista.

Vázquez Montalbán escribió Yo maté durante la etapa estética autodenominada por su autor como "escritura subnormal", en los años de la angustiosa y exasperante recta final del franquismo, cuando a las contradicciones de ser un intelectual de oficio en una sociedad de consumo gobernada por la comunicación de masas se le sumaban la contradicción fundamental de vivir en una distópica sociedad amordazada sin libertad y sin salida posible. La estética de la "subnormalidad" es la respuesta que Vázquez Montalbán ofrece para encararse a esa realidad de pesadilla, viviendo las contradicciones de ser un escritor amordazado en un estado sin derecho. La escritura vanguardista "subnormal” es el resultado de su desconfianza en el lenguaje del poder, la aniquilación subversiva de los códigos de comunicación establecidos y las formas narrativas tradicionales. En consecuencia, Yo maté es una novela de carácter experimental que no hace concesiones al lector, desafiando las convenciones narrativas, sin respetar las barreras genéricas, que cabría encajar dentro de los presupuestos de la llamada "anti-novela".

El ideario del Manifiesto subnormal de Vázquez Montalbán se podría representar esquemáticamente bajo la fórmula del trinomio o mènage-à-trois Marat-SadeFranco que el propio autor conceptualizó repetidamente. Al binomio de la célebre representación metateatral de Peter Weis, Marat-Sade, Vázquez Montalbán le añade la figura de Franco espiando tras las cortinas. En este nuevo reparto, Marat representaba la revolución colectiva política, Sade la revolución individual moral, y Franco el papel de vigilante y freno censor. Estas figuras actúan como referentes ideológicos y metafóricos de una situación histórica global, el periodo de guerra fría en que el reparto de poderes (o superpoderes) se realiza como una derivación deformada de sus principios, el imperio soviético revolucionario, el imperio americano del individualismo y, en tercer plano Franco, como autoproclamado centinela de los valores espirituales frente a la decadencia de Occidente.

Revista Iberoamericana, Vol. LXXVI, Núm. 231, Abril-Junio 2010, 477-492
ISSN 2154-4794 (Electrónico) 
Fruto de este simbólico mènage-à-trois, Carvalho sería uno de los primeros intelectuales "subnormales” y desencantados de la carrera literaria de Vázquez Montalbán, consciente de su condición de paralíticos, mutilados, impotentes frente a una cultura represiva y conscientes del fracaso de una propuesta de vanguardia reducidos a ser anomalías permitidas dentro del sistema. Recordemos la "prehistoria" de la trayectoria vital de Pepe Carvalho, que comenzó como intelectual del partido comunista y prisionero antifranquista, después como profesor universitario emigrado en Estados Unidos, antes de ser enganchado por la CIA, primero como colaborador más o menos inocente y luego como cínico agente internacional con licencia para matar. ${ }^{4}$ Sus misiones le llevan a los más recónditos lugares de Europa, Asia y América Latina. Años más tarde, el ex agente rememoraba cínicamente su intervención en la República Dominicana postrujillista:

Recordaba un viaje entre Santo Domingo y Sosúa en los tiempos en que estaba tratando de derrocar a Bosch en beneficio de Balaguer, a pesar de que había tratado fugazmente a Bosch en un congreso de rojos en el que le había infiltrado la CIA [...] lo derrocaron los americanos con la ayuda de Carvalho, aunque él se negara a presenciar el momento estricto del derrocamiento: ojos que no ven corazón que no siente y al fin y al cabo la inteligencia de todo progresista latinoamericano se demuestra asumiendo que está condenado a pender. (El premio 64)

La serie Carvalho se constituye propiamente como tal a partir de Tatuaje (1974), con Carvalho reciclado como detective privado en su Barcelona natal, en la recta final del franquismo. Pepe Carvalho se convierte en un disidente de ideologías y de grandes narrativas, desencantado, desclasado, descreído y de vuelta de todo, posicionado en un punto de vista marginal y transversal, convertido en un voyeur social y barómetro de la moral circundante, que Vázquez Montalbán instrumentaliza para ofrecer una radiografía vívida y satírica de la cultura contemporánea. El redescubrimiento en Tatuaje de este personaje instrumental mestizo, gallego-catalánamericano, ni de aquí ni de allá, in-between según la denominación de Bhabha, nómada fronterizo que se moverá por los barrios de Buenos Aires, Ámsterdam o Bangkok con la misma facilidad que en Barcelona, posibilita una óptica desde los márgenes que sirve de vértice para una nueva poética urbana a partir del desguace de las convenciones de la novela negra. Con la serialización de Carvalho, Vázquez Montalbán va a dar un gran salto copernicano de la "subnormalidad" a la serie negra que representa su entrada en la era de la postmodernidad y la globalización, coincidente con el final del franquismo y el comienzo de la Transición democrática.

4 No deja de ser significativo al respecto el paralelo de la biografía de Carvalho con la trayectoria de Galíndez, también un intelectual de la resistencia anti-franquista y emigrado que se adapta y acaba trabajando para los servicios secretos del "Imperio" americano.

Revista Iberoamericana, Vol. LXXVI, Núm. 231, Abril-Junio 2010, 477-492
ISSN 2154-4794 (Electrónico) 
La constitución de la serie Carvalho como tal evoluciona, así, de una estética de vanguardia modernista, a una estética posmoderna, aunque firmemente afianzada en una fuerte línea narrativa, que mezcla géneros y culturas high/low, y juega con las convenciones genéricas de manera irónica, autorreflexiva y desconfiada de las grandes narrativas de la historia.

La original aportación de la narrativa policíaca de Vázquez Montalbán reside en su hibridez genérica, que incluye el análisis político social y cultural del mundo contemporáneo, la preocupación por los desequilibrios en las relaciones de poder Norte-Sur, la política de bloques y las nuevas corrientes globalizadoras, los flujos migratorios y el imaginario narrativo del viaje. De igual manera que en Galíndez la acción se desplazaba del país Vasco, Madrid, Nueva York, Miami o Santo Domingo, en las novelas de Carvalho el detective ha de investigar una serie de misterios en diferentes rincones del planeta que le llevan, finalmente, a revelar su verdadero alcance político y social: la realidad de la emigración proletaria en Ámsterdam (Tatuaje), el turismo de masas y la evasión de capitales en Tailandia (Los pájaros de Bangkok, Roldán, vivo o muerto), la realidad miserable del trópico caribeño (La rosa de Alejandría), o los desaparecidos por la Junta militar en Argentina y la nueva conquista inversionista española de América Latina (Quinteto en Buenos Aires, Milenio Carvalho). La creación de nuevas identidades políticas, militares y económicas supranacionales, con la entrada de España en la OTAN y su plena incorporación en la Unión Europea, encuentra su respuesta en una lúcida y caricaturesca imagen de Europa como un club social para ricos frente a la presión demográfica inmigratoria en El balneario (1986). La original perspectiva montalbaniana, cargada de lucidez y afilada ironía, presta especial atención a las manifestaciones de la cultura popular y las prácticas de la vida cotidiana. Temas a primera vista triviales, como el deporte, la gastronomía o la moda, son objeto de atención y de reflexión crítica a partir de las cuales se revelan otras claves interpretativas de la realidad. Carvalho se convierte en el ojo crítico a través del cual el autor ofrece su radiografía cultural del momento histórico. Así, una simple observación gastronómica puede dar pie a una reflexión sobre la globalización cultural, la imposición de homogeneidad y la erradicación de la diferencia, desde una perspectiva profundamente irónica:

-A mí me sacan de la hamburguesa, y me pierdo.

Y eso que aún no estamos en la OTAN, pensó Carvalho. En cuanto nos metan en la OTAN lo primero que van a instalar van a ser oleoductos de catsup y de mostaza. ("El barco fantasma” 77)

Igualmente, Vázquez Montalbán ha examinado de cerca en la serie Carvalho la imparable globalización de Barcelona, recurriendo a la imagen de la reconstrucción

Revista Iberoamericana, Vol. LXXVI, Núm. 231, Abril-Junio 2010, 477-492
ISSN 2154-4794 (Electrónico) 
de la ciudad como metáfora de los cambios acaecidos durante el periodo de la postransición democrática marcada por la globalización, especialmente intensificados desde la entrada de España en organizaciones supranacionales, como la OTAN y la Unión Europea. De esta forma, ha reflejado la esencial desigualdad del fenómeno global de los flujos de masas, entre el turismo del Norte y la inmigración del Sur -El delantero centro será asesinado al atardecer (1988)-, y la transformación de la ciudad en un escenario de espectáculo para consumo global a raíz de los Juegos Olímpicos -El laberinto griego (1991), Sabotaje olímpico (1993), El hombre de mi vida (2000)- con el enorme impacto local consiguiente. A propósito de El hombre de mi vida, Quim Aranda resume así el resultado de la globalización ideológica, política, económica y cultural en umbral del nuevo milenio:

Tiempos globales definidos por el alma de globalizadores, tiempos en los que no encajan ni los outsiders ni los nacionalistas, donde éstos son manipulados con tierras prometidas y nuevas religiones: Globalizadores antes de un pelaje, ahora de otro, siempre de la misma calaña, porque "las centrales de policía ni se crean ni se destruyen, simplemente repintan sus fachadas". Y quien dice "centrales de policía” dice conversos al economicismo triunfante. ("Carvalho contra los globalizadores”)

Tanto en sus novelas policíacas como en el resto de sus escritos y declaraciones, Vázquez Montalbán no deja duda de su posicionamiento ideológico que reclama el derecho a la disidencia y a la réplica al sistema. Se sitúa así más allá de las ambiguas posiciones intermedias ante la globalización por parte de ciertos críticos culturales, como García Canclini, desconfiado de los radicales planteamientos "binaristas" y más interesado en descifrar los procesos de hibridación multicultural y las transacciones e interacciones transnacionales que en las prácticas de confrontación y transformación de los desequilibrios de fuerzas:

Ni los grupos hegemónicos se dedican exclusivamente a dominar y destruir, ni los oprimidos a resistir y enfrentar. [...] Aunque ciertas confrontaciones tengan el aspecto de simple oposición y la globalización exaspere desigualdades (y cree otras), ningún grupo actúa todo el tiempo como si la vida social se redujera a una guerra incesante. (García Canclini 87)

No debe resultar extraño, por ello, que la despedida final de la serie (Milenio Carvalho I y II), novela anunciada con casi 30 años de anticipación y publicada póstumamente en 2004, sea precisamente un largo periplo alrededor del mundo contemporáneo que examina el triste legado del colonialismo europeo en cuatro continentes y constituye una furibunda reflexión crítica sobre los efectos nocivos de la globalización desde una perspectiva que podríamos calificar de poscolonial.

Revista Iberoamericana, Vol. LXXVI, Núm. 231, Abril-Junio 2010, 477-492
ISSN 2154-4794 (Electrónico) 
Así, la novela, frente a la mirada complaciente y exotizante de la literatura colonial de viajes, va tomando la presión al clima actual de violencia política en el Medio Oriente, las ofensivas del terrorismo y el contraterrorismo, el paisaje después de la batalla en Afganistán, los paraísos perdidos orientales, las antípodas, la postergada eterna promesa americana del Cono Sur y Brasil, para terminar en la miserable y terrible realidad del África negra antes de volver al punto de partida inicial. En palabras del autor, "Milenio no es sólo un viaje geopolítico, sino una angustiada peregrinación laica por un mundo cada vez más hipócritamente religioso, convocados todos los días los dioses para justificar guerras santas y hegemonías económicomilitares" ("La historia de Milenio"). Milenio presenta, entonces, toda una galería humana de verdugos y víctimas de la globalización, la nueva fase neocolonial de un nuevo orden internacional que produce una desigual división de poderes entre los sujetos y los objetos de la globalización, como resume unos de los personajes de la novela, el conocido teólogo de la liberación brasileño Frei Betto: "La misma palabra 'globalización' es, aparentemente, sólo descriptiva de unas relaciones de producción e intercambio realmente globalizadas. Pero no lo dice todo. Porque en esa supuesta obviedad enunciativa, unos son los globalizadores y otros los globalizados” (Vázquez Montalbán, Milenio II 266).

Construida como un conglomerado collage de discursos heterogéneos y heteroglósicos, en los que tiene cabida la parodia, el análisis político y cultural, la cita y la autoreflexividad, la serie Carvalho propone un nuevo modelo de novela policíaca posmodernista que atraviesa las fronteras culturales nacionales y lingüísticas. Tanto en el ámbito latino, como en el europeo, su influencia ha sido muy importante. Como los más grandes creadores revolucionarios, Vázquez Montalbán trastocó el género policíaco, lo redefinió y se convirtió, al mismo tiempo, en su nuevo prototipo, el referente ejemplar de una nueva manera de hacer novela policíaca en español. Su obra ha contribuido de manera esencial a la legitimación de este género, especialmente en el mundo hispánico y en el sur de Europa, desde Grecia hasta Portugal y, especialmente, en Francia e Italia, donde Vázquez Montalbán llegó a ser un intelectual ídolo de masas y sus libros obligatorios best-sellers en todos los kioscos, como ha señalado su traductora al italiano (Lyra, "El estigma”). Es incalculable su influencia sobre la obra de muchos novelistas policíacos contemporáneos, tanto en español (Francisco González Ledesma, Juan Madrid, Eduardo Mendoza, Paco Ignacio Taibo II) como en otras lenguas. ${ }^{5}$ Como reciente botón de muestra del

5 Para un análisis de la estrecha relación de Taibo II con Montalbán, véase Colmeiro, “The Hispanic (Dis)Connection”. La nómina de autores que se adhesionan al homenaje a Carvalho en su 25 aniversario incluía desde escritores en posiciones ideológicas antagónicas como Fernando Savater o Mario Vargas Llosa, a escritores en posiciones estéticas divergentes como Pere Gimferre o Jorge Amado. Véanse los libros colectivos A Vázquez Montalbán y Carvalho y A Vázquez Montalbán y Carvalho.

Revista Iberoamericana, Vol. LXXVI, Núm. 231, Abril-Junio 2010, 477-492
ISSN 2154-4794 (Electrónico) 
alcance global y la influencia de la obra policíaca de Vázquez Montalbán, en el mes de enro de 2005 se celebró en Barcelona un homenaje internacional en su honor por parte de los novelistas policíacos europeos, tales como el griego Petros Márkaris, la americano-italiana Donna Leon y la portuguesa-angoleña Filipa Melo, entre otros muchos que se consideran deudores de la serie Carvalho. Así lo expresaba Márkaris, cuyas palabras bien pudieran aplicarse a tantos otros continuadores de la obra del novelista pionero catalán: "De Vázquez Montalbán aprendí a mirar la ciudad y, sobre todo, a utilizar el sarcasmo y el cinismo como forma de supervivencia. El, que como yo vivió bajo un régimen opresivo, me enseñó cómo incluir la política dentro de la novela" (Obiols 30). ${ }^{6}$

De todas las proclamaciones de adhesión a la obra policíaca de Vázquez Montalbán, sin duda, una de las más sorprendentes ha de ser la protagonizada por el Subcomandante Marcos, jefe del movimiento de liberación zapatista en Chiapas (FLZN). Lo cierto es que el autor y el revolucionario, a pesar de las evidentes diferencias que separan a un intelectual burgués europeo de un armado revolucionario indigenista latinoamericano, han compartido gustos literarios, una sólida formación política e intelectual y muy similares planteamientos y posiciones críticas frente a la globalización. De hecho, uno de los libros de Vázquez Montalbán más combativos sobre la globalización, Panfleto desde el planeta de los simios, es un referente repetido en los comunicados de Marcos. A lo largo de los años de la revuelta zapatista, ambos han mantenido una relación de intercambio intelectual, fundamentada en el interés y el aprecio mutuos, y marcada por la ironía y la agudeza. Convendría hacer un relato de las comunicaciones mantenidas entre ambos, ya que revela la utilización táctica de los medios que la globalización pone al alcance, desde una postura crítica y de oposición a los efectos negativos de su imposición. Al poco tiempo del levantamiento en Chiapas, Marcos confesó insospechadamente, en una entrevista a la TVE, que había decidido dejar de leer las novelas de Carvalho porque excitaban apetitos que no podían ser satisfechos en la selva. Vázquez Montalbán toma nota del mensaje de ultramar y se solidariza con Marcos en un guiño irónico no carente de simpatía. Como el mismo escribiría años más tarde con su característica nota sardónica, después de leer varios testimonios en los que se documentaban las condiciones reales en las que vivían los integrantes del movimiento, se hace consciente del deber ético de no contribuir al desánimo de los indígenas luchadores contra la globalización: “comprendí que Carvalho y sus manías gastronómicas podían constituir una quinta columna, más peligrosa que todos los impugnadores del subcomandante juntos” (Marcos 21). Por tal motivo, Vázquez Montalbán publicó un escrito en El País en 1997, “en que le prometía al

6 Para un catálogo de adhesiones apasionadas hacia la obra de Vázquez Montalbán por parte de la intelectualidad italiana, véase Il viaggio in Italia de Hado Lyra.

$\begin{array}{llllll} & \text { Revista Iberoamericana, Vol. LXXVI, Núm. 231, Abril-Junio 2010, 477-492 }\end{array}$ 
subcomandante incluir cocina de supervivencia o precolombina en mis novelas, comidas profundas en la selva Lacandona” (Marcos 21). La respuesta de Marcos no se hizo esperar. Al poco tiempo, el Subcomandante Marcos escribió una carta dual a Pepe Carvalho y Vázquez Montalbán, reconociéndose fervoroso lector y admirador de su saga policíaca, e invitándolo a un encuentro en la Sierra Lacandona. En su carta, Marcos también se confesaba como autor policíaco a imitación de las hazañas de Pepe Carvalho: "No le guardo rencor por la tortura que significó para mí, en aquellos primeros años de montaña (1984-1990) la lectura de sus aventuras gastronómicas, policíacas y amorosas. Tan no le guardo rencor que estoy preparando un largo texto que, seguro estoy, hará las delicias de chicos y grandes cuando vean que el Pepe Carvalho y el Sup resuelven, por globalizada correspondencia, un complicado caso criminal [...]” (Marcos 23). Vázquez Montalbán, para quien la revolución zapatista había sido objeto de gran atención desde sus inicios, continúa la "globalizada correspondencia" enviándole un lote de libros a la selva Lacandona, en espera de un futuro encuentro. A principios de 1999, Marcos se comunica nuevamente y conciertan el encuentro en la selva, adonde el autor catalán le llevará alguno de sus libros, amén de una muestra representativa de chorizos y turrones españoles para suplir las necesidades espirituales y materiales. De la serie de conversaciones que se produjeron en ese encuentro Vázquez Montalbán dio a luz un libro-reportaje, Marcos: el señor de los espejos, y toda una serie de escritos y conferencias en las que reflexionaba sobre el movimiento zapatista como metáfora de la resistencia frente a la globalización. El encuentro también daría pie a un malogrado proyecto de colaboración literaria. Marcos, letrado con veleidades literarias, le propondría a Vázquez Montalbán escribir una novela policíaca a medias, algo que el autor catalán aceptó de buen grado pero que no se pudo llevar a cabo debido a su prematura muerte. ${ }^{7}$ El propio Marcos recordaba este naufragado proyecto en su emotiva carta leída en la Feria del libro Guadalajara en 2004, proyecto que finalmente realizó con Paco Ignacio Taibo II, como homenaje póstumo al autor catalán:

En alguna misiva le propuse a Don Manuel Vázquez Montalbán escribir una novela policíaca “a la limón”, con unas partes escritas en las montañas del sureste mexicano y otras en las Ramblas catalanas. El aceptó, aunque, lo confesó alguna vez, no tenía la menor idea de cómo eso sería posible. Yo tampoco, pero esto ya no lo supo. Próximamente el Sistema Zapatista de Televisión Intergaláctica, “la única televisión que se lee”, transmitirá el primer capítulo de una serie policial que como todo lo zapatista, tiene un futuro incierto. Es el pequeño homenaje que,

7 Para amplificar su mensaje mediático, Marcos ya había anteriormente enviado unos versos suyos al cantautor español Joaquín Sabina, otro declarado crítico de la globalización, con la intención de que los convirtiera en una canción escrita a medias. Esta vería la luz en su disco Dímelo en la calle (2002), con el título “Como un dolor de muelas".

Revista Iberoamericana, Vol. LXXVI, Núm. 231, Abril-Junio 2010, 477-492
ISSN 2154-4794 (Electrónico) 
durante meses, le hemos preparado a él. Seguramente será poco, y la calidad literaria no se acercará siquiera a sus magníficas producciones, pero es nuestra forma de hacerle saber, a quienes lo acompañaron en vida, que, cuando abrimos alguno de sus muchos libros, no sólo lo leemos, también y a nuestro modo, cruzamos hacia él, es decir, lo abrazamos. (“A Manuel Vázquez Montalbán”)

Efectivamente, la novela apareció en forma serializada con el título de Muertos incómodos (falta lo que falta) en el periódico mexicano La Jornada a lo largo de doce semanas, entre finales de 2004 y principios de 2005, y posteriormente se publicó como libro en múltiples ediciones y en traducciones a otros idiomas. La versión cibernética de la novela se hizo también inmediatamente disponible en su totalidad en muchas páginas gratuitas de Internet alrededor del globo. Muertos incómodos constituye un experimento literario y de estrategia política en la era de la globalización, como producto de la colaboración a distancia entre dos autores, utilizando el email, el internet y la prensa periódica para difundir una visión crítica, e incluso abiertamente panfletaria, de la realidad globalizada.

En la novela, "escrita a cuatro manos", se difuminan los contornos genéricos tradicionales en un conglomerado híbrido, con elementos de novela policíaca, el testimonio y el panfleto. Es una novela de desaparecidos y detectives marginales, de víctimas y fantasmas, de crítica abierta al neoliberalismo, la sociedad patriarcal, y todas las formas de subyugación. Como las propias novelas policíacas de Vázquez Montalbán, Muertos incómodos está constituida como un collage narrativo, de diferentes lenguajes heterogéneos, en el que tienen cabida la reflexión política, la crónica social, el humor, la parodia e, incluso, la gastronomía cultural, en un evidente guiño a la serie Carvalho. Novela policíaca cervantina y posmoderna, llena de citas intertextuales, personajes históricos reales y metaficcionales, en los que las figuras de Carvalho y Vázquez Montalbán aparecen repetidamente de manera fantasmagórica, como otros muertos incómodos que se resisten a desaparecer en la novela, enviando notas desde la ultratumba, a manera de un Capitán Nemo posmoderno. Es así que el narrador llega finalmente a preguntarse "¿Era todo el guión de una novela de Manuel Vázquez Montalbán con Carvalho en México?” (Capítulo 8).

De esta forma, la novela policíaca, de manera similar a las canciones de Manu Chao, o los propios comunicados de Marcos, se convierte en un puente de acercamiento, de encuentro y de hibridación cultural, de instrumento de intervención pública en la sociedad y de reivindicación social, de crítica a la globalización y, a la vez, de resistencia a la imposición de homogeneidad, utilizando los mismos medios que la globalización ha puesto a su alcance.

8 Sobre la orquestación comercial del “Año Carvalho” por parte de Planeta y su construcción mediática como fenómeno global, véase Colmeiro, "The Hispanic (Dis)Connection”.

Revista Iberoamericana, Vol. LXXVI, Núm. 231, Abril-Junio 2010, 477-492
ISSN 2154-4794 (Electrónico) 
En el ámbito popular, al igual que en el literario o el académico, la obra de Vázquez Montalbán también ha tenido un alcance global y ha sido objeto de mitificación y de comodificación. ${ }^{8}$ La serie Carvalho ha sido llevada al cine y a la televisión repetidas veces, con mayor o menor fortuna y hasta en múltiples versiones, dirigida por directores españoles como Bigas Luna y Vicente Aranda, argentinos comoAdolfo Aristaraín y Luis Baroné, los franceses Philippe Vernault, Emmanuelle Cuau, Fabrice Cazeneuve y Laurent Jaoui, el argelino Merzak Allouache y el italiano Franco Giraldo, y ha gozado de un reparto artístico internacional con actores españoles, italianos, franceses y portugueses. Dado el enorme éxito popular de la serie Carvalho y su repercusión a nivel internacional en otros soportes extraliterarios, se podría decir que Pepe Carvalho ha superado los límites de la página impresa para entrar en la galería de mitos colectivos contemporáneos. De hecho, la fama de Pepe Carvalho ha traspasado las páginas de ficción de su autor, para aparecer fantasmalmente en las obras de otros autores contemporáneos, tales como Juan Madrid y Andreu Martín en España, o Paco Ignacio Taibo II (La vida misma) en México. En Italia, Andrea Camilleri ha nombrado a su investigador Montalbano, en directo tributo a la obra del autor catalán. De esta manera, Carvalho ha conseguido situarse en el olimpo de mitos colectivos populares del siglo xx, de los que se alimentaba la educación sentimental y la literatura de Vázquez Montalbán, junto a los hermanos Marx (Groucho, Harpo y Carlos, siempre fueron sus favoritos), la familia Kennedy, Mao, Castro, Conchita Piquer, Humphrey Bogart, Antonio Machín, el Che y el Pato Donald. Algo que ocurre pocas veces, Pepe Carvalho ha logrado trascender los límites del hecho estrictamente literario, para convertirse en un auténtico fenómeno cultural a escala global.

El alcance del fenómeno cultural "Carvalho" a nivel internacional se extiende de lo más sublime a lo más kitsch. A Carvalho se le han dedicado sonetos, así como infinidad de artículos y tesis doctorales, se le han organizado páginas web y congresos literarios, al igual que se le han hecho caricaturas, canciones e historietas, adaptaciones teatrales, televisivas y cinematográficas; e incluso lo han comercializado en forma de rompecabezas de mesa, cuadernos de notas, postales, libros conmemorativos o lujosas enciclopedias gastronómicas de regalo. En resumen, la serie policíaca de Vázquez Montalbán se desarrolla en una tensión permanente entre la comodificación como mercancía exportable, como los chorizos o los turrones, y la legitimidad de su canonización literaria, ofreciendo al mismo tiempo una irónica galería de respuestas críticas frente a los efectos negativos de la globalización. A falta de respuestas terminantes, quedan sin embargo las preguntas abiertas.

No hay verdades únicas, ni luchas finales, pero aún es posible orientarnos mediante las verdades posibles contra las no verdades evidentes y luchar contra ellas. Se puede ver parte de la verdad y no reconocerla. Pero es imposible contemplar el

Revista Iberoamericana, Vol. LXXVI, Núm. 231, Abril-Junio 2010, 477-492
ISSN 2154-4794 (Electrónico) 
mal y no reconocerlo. El Bien no existe, pero el Mal me parece o me temo que sí. (Vázquez Montalbén, Panfleto desde el planeta de los simios 145)

BiBliografía

Aranda, Quim. “Carvalho contra los globalizadores”. <http://www.vespito.net/ $\mathrm{mvm} / \mathrm{hmv1}$.html>

Arco, Juan del. “El detective no puede llamarse Fernández”. El Español (Madrid, 18 de septiembre de 1948).

Bhabha, Homi. The Location of Culture. Londres: Routledge, 1994.

Bourdieu, Pierre. The Field of Cultural Production. Nueva York: Columbia UP, 1993.

Brau, Hèctor. "Manolo dixit". La Vanguardia (26 de octubre de 2003). <http:// www.vespito.net/mvm/entr9.html>

Colmeiro, José F. Crónica del desencanto: La narrativa de Manuel Vázquez Montalbán. Coral Gables: University of Miami, North-South Center, 1996.

"The Hispanic (Dis)Connection: Some Leads and a few Missing Links". Journal of Popular Culture 34/3 (2001): 51-68.

García Canclini, Néstor. La globalización imaginada. México: Paidós, 2000.

Friera, Silvina, "El libro que hicimos es un llamado de atención del EZLN". Página/12 (23agosto 2005). <http://www.pagina12.com.ar/diario/suplementos/ espectaculos/4-213-2005-08-23.html>

Holquist, Michael. "Whodunit and Other Questions: Metaphysical Detective Stories in Postwar Fiction”. The Poetics of Murder. Glenn N. Most y William E. Stone, eds. San Diego: Harcourt, 1983.

Lyra, Hado. Il viaggio in Italia. Omaggio del Premio Grinzane a Manuel Vázquez Montalbán. Piacenza: Frassinelli, 2004.

"El estigma de aquella adolescencia” Manuscrito inédito, 2005.

Marcos. “A Manuel Vázquez Montalbán”. Cartas y comunicados del EZLN. Texto enviado por el SCI Marcos del EZLN, para ser leído en el homenaje que se rindió a Manuel Vázquez Montalbán en la Feria Internacional del Libro de Guadalajara, Jalisco, México, el 28 de noviembre del 2004. <http://www.fzln. org.mx/displayarticle1179.html>

Marcos, Subcomandante y Paco Ignacio Taibo II. Muertos incómodos (Falta lo que falta). La jornada (5 de diciembre de 2004 al 20 de febrero de 2005). < http:// www.jornada.unam.mx/incomodo/incomodo.php>

"A Brief (Happy) Talk with Paco Ignacio Taibo II (Latin America: Private Eyes \& Time Travelers) (Interview)”. The Literary Review 38/1 (Fall 1994): 33-44.

Revista Iberoamericana, Vol. LXXVI, Núm. 231, Abril-Junio 2010, 477-492 
Obiols, Isabel. "Los novelistas policíacos europeos rastrean los escenarios de Carvalho”. El País (22 de enero de 2005): 30.

Sanz Villanueva, Santos. “Carvalho, pequeñoburgués”. El Mundo (19 de abril de 2000) <http://www.vespito.net/mvm/hmv2.html>

Stavans, Ilán. “An Appointment with Hector Belascoarán Shayne, Mexican Private Eye (A Profile of Paco Ignacio Taibo II)”. Review of Latin American Literature and Arts 42 (junio 1990): 5.

Taibo II, Paco Ignacio. “La ‘otra’ novela policíaca”. Los Cuadernos del Norte 8/41 (1987): 36-41.

Valls, Fernando. “La comedia humana de Carvalho”. El País. Edición de Cataluña (30 de junio de 1997). <http://www.vespito.net/mvm/comedia.html>

Vázquez Montalbán, Manuel. “Elbarco fantasma”. Historias de fantasmas Barcelona: Planeta, 1986. 61-113.

El premio. Barcelona: Planeta, 1996.

“La historia de Milenio” El País (3 de agosto de 2002). < http://www.vespito. net/mvm/milenio00.html>

Marcos: El señor de los espejos. Madrid: Santillana, 1999.

Milenio Carvalho II. En las antipodas. Barcelona: Planeta, 2004.

Panfleto desde el planeta de los simios. Barcelona: Crítica, 1995.

“Porto Alegre: entre Davos y Guantánamo”. El País (3 de febrero de 2002) $<$ http://www.vespito.net/mvm/portoalegresp.html>

“Respuesta a Agustín Ávila”. (Marzo de 2000) <http://www.vespito.net/ mvm/chiapas11.html>

“Un nuevo internacionalismo”. El País, Revista de Agosto (2 de agosto de 2000) <http://www.vespito.net/mvm/internac.html>

VV.AA. “A Carvalho y Vázquez Montalbán. Dedicatorias I”. Carvalho 25 años. Estuche Conmemorativo. Manuel Vázquez MontalbánBarcelona: Planeta, 1987.

VV.AA. “A Vázquez Montalbán y Carvalho. Dedicatorias II”. Carvalho 25 años. Estuche Conmemorativo. Manuel Vázquez Montalbán. Barcelona: Planeta, 1987.

\footnotetext{
Revista Iberoamericana, Vol. LXXVI, Núm. 231, Abril-Junio 2010, 477-492 